\title{
Scanning Electron Microscopy (SEM) Analysis and Hardness of Diffusion Bonded Titanium-Titanium and Titanium-Copper Plates with Static Force and without Interlayers
}

\author{
Joel Hemanth \\ Department of Mechanical Engineering, H.M.S. Institute of Technology, Tumkur, India \\ Email: joelhemanth@hotmail.com
}

How to cite this paper: Hemanth, J. (2017) Scanning Electron Microscopy (SEM) Analysis and Hardness of Diffusion Bonded Titanium-Titanium and Titanium-Copper Plates with Static Force and without Interlayers. Open Journal of Composite Materials, 7, 105-116.

https://doi.org/10.4236/ojcm.2017.72007

Received: February 25, 2017

Accepted: April 27, 2017

Published: April 30, 2017

Copyright $\odot 2017$ by author and Scientific Research Publishing Inc. This work is licensed under the Creative Commons Attribution International License (CC BY 4.0).

http://creativecommons.org/licenses/by/4.0/

(c) (i) Open Access

\begin{abstract}
In the present research, commercially pure $\mathrm{Ti}$ (grade-2) has been diffusion bonded with $\mathrm{Ti}$ and $\mathrm{Cu}$ plate under static force without any interlayers. The diffusion bonded samples were tested for micro hardness and micro structural analysis through optical microscopy and SEM. It is found from the present investigation that the bonded zone is affected by the processing variables such as bonding time $(1-2 \mathrm{~h})$, bonding force $(250 \mathrm{~N})$, bonding temperature (973 $1073 \mathrm{~K})$ and surface roughness. Results of the investigation revealed that temperature range of -973 - $1073 \mathrm{~K}$ along with time duration of $1-2$ hours in vacuum has resulted in a joint having high hardness with minimum pores. Hardness of the bond depends on the grain boundary diffusion at the interface and maximum hardness was achieved in the case of $\mathrm{Ti}-\mathrm{Cu}$ joints. When Ti-Cu plates were used for bonding at $973 \mathrm{~K}$ for 2 hours, $\mathrm{Cu}$ - $\mathrm{Ti}$ solid solution along with a zone of different intermetallics was formed in the bonded zone. However, at higher temperatures, no continuous zone of intermetallics was found in the bonded region but instead Ti-Cu solid solution appeared.
\end{abstract}

\section{Keywords}

Diffusion Bonding, Titanium, Micro Hardness, Surface Roughness,

Microstructure

\section{Introduction}

Diffusion Bonding (DB) technique is based on the atomic diffusion of elements 
at the joining interface and the process actually is the transport of mass in the form of atomic movement or diffusion through the lattice of a crystalline solid. Diffusion bonding is the solid state metal joining process comprising of similar and dissimilar metals or non-metals. Diffusion of atom occurs by many mechanisms such as exchange of places between adjacent atoms, motion of interstitial atoms or motion of vacancies (unoccupied site) in a crystalline lattice structure. Macroscopic deformation in a diffusion controlled process is induced by applying definite heat and pressure for a finite interval of time and the preferable mechanism involved here is the low activation energy required for atomic movement [1] [2]. Diffusion of atoms is a thermodynamic process where temperature and infusibility of the material are considerable parameters. In general, the diffusion rate [3], in terms of diffusion coefficient $\mathrm{D}$ is given by the well known Fick's law of diffusion.

The aerospace industry is a larger market for titanium products primarily due to the exceptional specific strength, corrosion resistance and high resistance and elevated temperature properties [4] [5]. With increased use of $\mathrm{Ti}$ and its alloys, the joining of $\mathrm{Ti}$ and its alloys is of great interest. Unfortunately welding of $\mathrm{Ti}$ and its alloys is very difficult as they are highly reactive at high temperatures and tend to oxidize with oxygen [6] [7] [8]. Brazing is an effective method for dissimilar materials joining, but the brazing joint of $\mathrm{Ti}$ is difficult to guarantee access to the entire surface of the joint continuity [9]. Therefore, diffusion bonding becomes a popular and preferred solid-state joining process for $\mathrm{Ti}-\mathrm{Ti}$ and $\mathrm{Ti}-\mathrm{Cu}$ because the coalescence of contacting surfaces occurs with minimum along with high joining quality.

The quantitative treatment of unsteady state diffusion processes is also formulated and one can consider it to examine some relevant solutions quantitatively. Oxidation rate constant follows an Arrhenius relationship and the effective activation energy for oxidation was obtained from the Arrhenius plot. The activation energy for the titanium material is improved by heating the specimen almost near the recrystallization temperature. At higher temperature, creep problems can be eliminated by creating the inert atmosphere through the use of rotary and diffusion pumps. Figure 1 shows the diagram indicating steady state and unsteady state diffusion bonding process.

The activation energy for atomic diffusion at the surface, interface and grain boundaries is relatively low compared to the bulk diffusion due to a looser bond of the atoms and higher oscillation frequency of the diffusing atom. This enhances

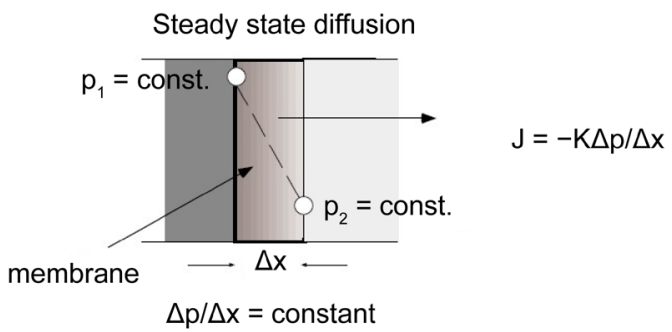

Non-steady state diffusion

Figure 1. Steady state and unsteady state diffusion bonding. 
the atomic diffusion, and thus eases the diffusion bonding of two metal pieces assuming that a perfect interface contact exists. The interface contact can be optimized by a treatment of the surface to be bonded through a number of processes, such as mechanical machining, polishing, etching, cleaning and coating. Creep mechanism allows a material flow to produce full intimate contact at the joint interface as required for diffusion bonding. Therefore, surface treatment and selection of bonding temperature and loading are basically important factors for the diffusion bonding process. Other factors such as thermal conductivity, thermal expansion, and bonding environment also affect the bonding process, particularly at high bonding temperature.

Many reports on diffusion bonding and transient liquid phase bonding of $\mathrm{Ti}$ and its alloys have been published [10].

The optimum bonding strength occurred at $850^{\circ} \mathrm{C}$ for 90 min when an $\mathrm{Ag}$ $\mathrm{Cu}-\mathrm{Zn}$ interlayer was used along with the formation of intermetallics in the bond line [11]. Kundu et al. [12] conducted diffusion bonding of Ti to 304 stainless steel using $\mathrm{Cu}$ interlayers. Dezellus et al. [13] performed transient liquid phase bonding of $\mathrm{Ti}$ to $\mathrm{Al}$ nitride using a Cusil $(28 \mathrm{Cu}-\mathrm{Ag})$ interlayer. In this bonding process, $\mathrm{Ti}$ formed different intermetallics with $\mathrm{Cu}$. $\mathrm{Cu}$ alloy is widely used in aviation, navigation and automobile industries because of its good elasticity, high strength and good abrasive resistance. In some locations, the performance requirements for titanium and $\mathrm{Cu}$ alloy components are special. So the bonding of titanium with $\mathrm{Cu}$ form a compound structure which reduces the mass of structure. Therefore, study on the technology for bonding of titanium with $\mathrm{Cu}$ is of great importance. However, the properties of $\mathrm{Ti}$ and $\mathrm{Cu}$ have great differences in crystal structure, melting point, heat conductivity, and linear expansion coefficient. Thus, the traditional fusion method is hard to realize the joining process.

In the present research the joining of $\mathrm{Ti}-\mathrm{Ti}$ and $\mathrm{Ti}-\mathrm{Cu}$ alloy is realized by diffusion bonding to fabricate composite structure without any interlayer has open up a new way to broaden the application of titanium and copper alloys. Hence the focus of the present investigation is aimed at vacuum diffusion bonding of $\mathrm{Ti}-\mathrm{Ti}$ and $\mathrm{Ti}-\mathrm{Cu}$ alloy to realize the resulting hardness and microstructural characteristics at the interfacial zone of specimens tested after bonding at different temperatures and exposure times.

\section{Experimental Procedure}

Diffusion bonding process of commercially pure $\mathrm{Ti}$ and $\mathrm{Cu}$ plates without any interlayers was conducted in a vacuum thermal-imitation machine and the working chamber was evacuated to a pressure of $1.1 \times 10^{-3} \mathrm{~Pa}$. Figure 2 and Figure 3 shows the diffusion bonding process diagram as well as the experimental setup. This set up includes a vacuum chamber to minimize the chemical reaction during the bonding process by creating the necessary vacuum using the rotary pump and a diffusion pump along with a furnace as the heating system. Diffusion pump and vacuum chambers are continuously cooled through water 


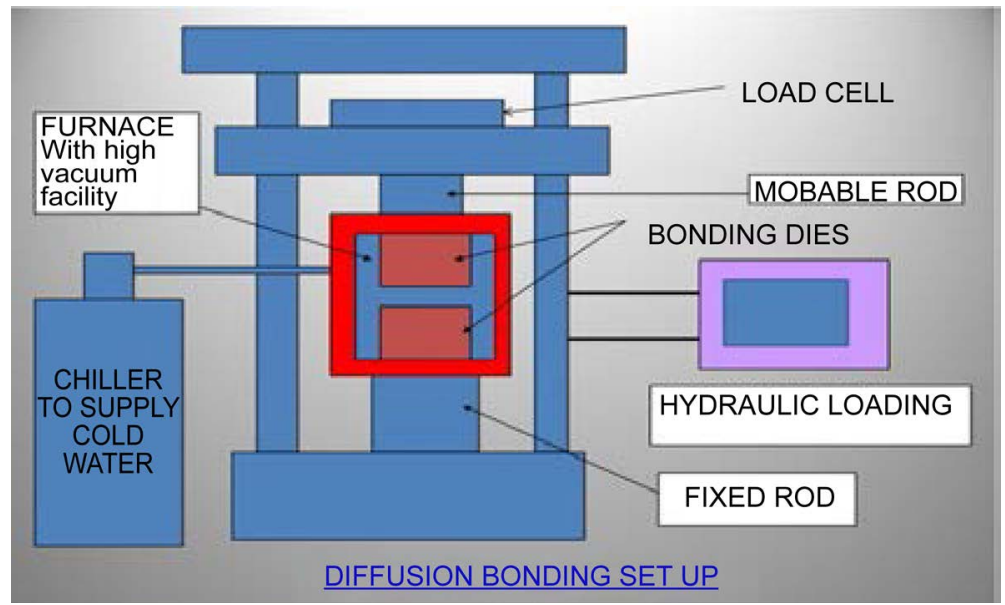

Figure 2. Diffusion bonding processes diagram.

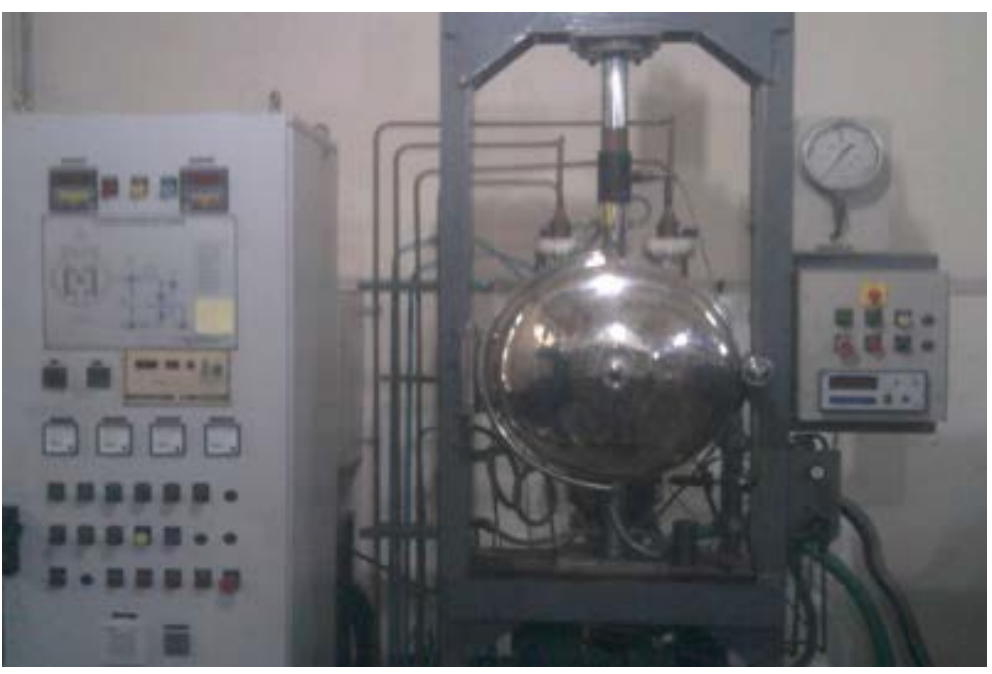

Figure 3. Diffusion bonding experimental set-up.

circulation system with a pump and chillers. The required force on the specimens during bonding is applied using hydraulic loading mechanism. Ti-Ti joints were bonded at $1073 \mathrm{~K}$ for $1-2 \mathrm{~h}$ and $\mathrm{Ti}-\mathrm{Cu}$ were bonded at $973 \mathrm{~K}$ for $1-2 \mathrm{~h}$ both under a static force of $250 \mathrm{~N}$. Plate type of specimens of size $20 \times 10 \mathrm{~mm}$ and of thickness $3 \mathrm{~mm}$ were used for diffusion bonding and subsequent hardness and microstructural examination. The mating surfaces of the specimens were ground with $\mathrm{SiC}$ (emery) polished using diamond paste and finally cleaned in an ultrasonic bath using acetone reagent acetone for 30 seconds before bonding. The surface roughness of the prepared specimens was finally measured using a standard electronic surface roughness profile meter. The samples to be bonded were held in a jig made of Ti (to avoid the thermal expansion mismatch) under static force and placed in a diffusion bonding furnace.

A longitudinal section of each bonded sample was polished for microstructural observation. Neophot -21 metallurgical microscope was used for optical microscopy of the polished sepcimens. Scanning electron microscopy (SEM) observations were carried out using JEOL K-8140B scanning electron microscope 
and the composition of different phases in the bonded zone were analyzed by EDS method. To determine the mechanical property of the bonded specimens micro hardness tests were performed on the right and left side of the bonded area using a Hitachi make micro hardness tester.

\section{Results and Discussion}

\subsection{Surface Roughness and SEM Fracture Analysis}

In addition to bonding temperature, bonding time, bonding force, flatness and roughness of the bonding surfaces were found to influence the hardness of the diffusion bonded joints. Figure 4 and Figure 5 shows the surface roughness profile of ground and polished $\mathrm{Ti}$ and $\mathrm{Cu}$ plates. The surface roughness value in terms of Ra was measured using the standard procedure. This was done using with different grades of emery papers of which emery papers of grade above 2000 along with polishing (using diamond paste) gave very smooth surface having no surface irregularities and aspirates. This is very important for atomic diffusion and hence the bond hardness. Figure 6 and Figure 7 shows the SEM images of the fractured surfaces (under tension) of Ti-Ti bonded at $1073 \mathrm{~K}$ and

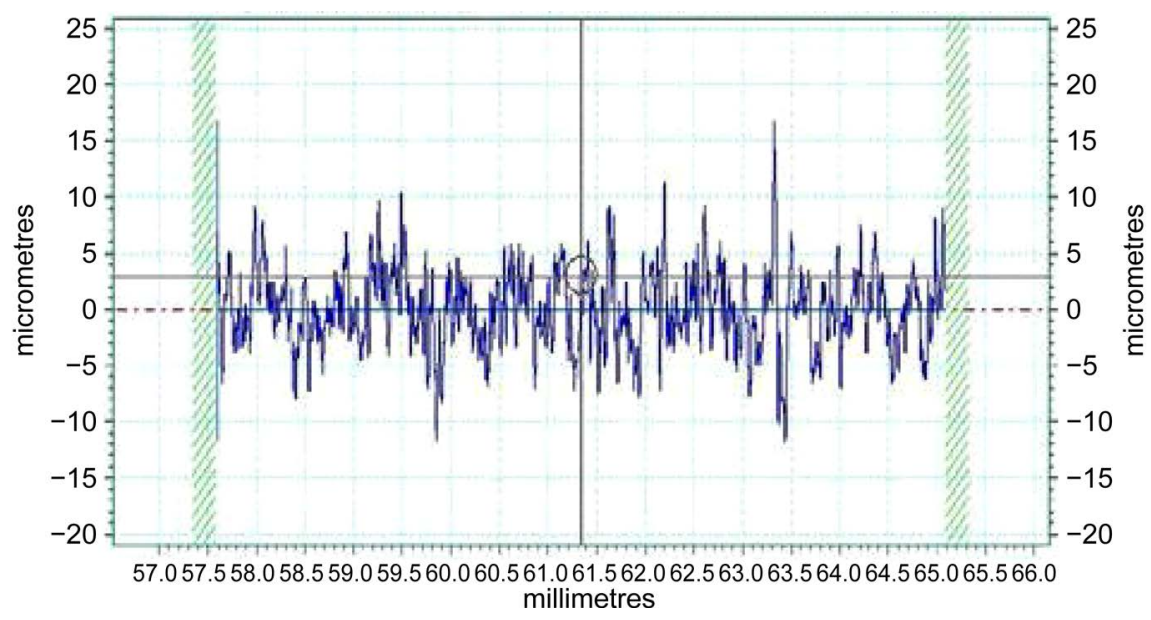

Figure 4. Surface roughness profile of Ti plate before bonding.

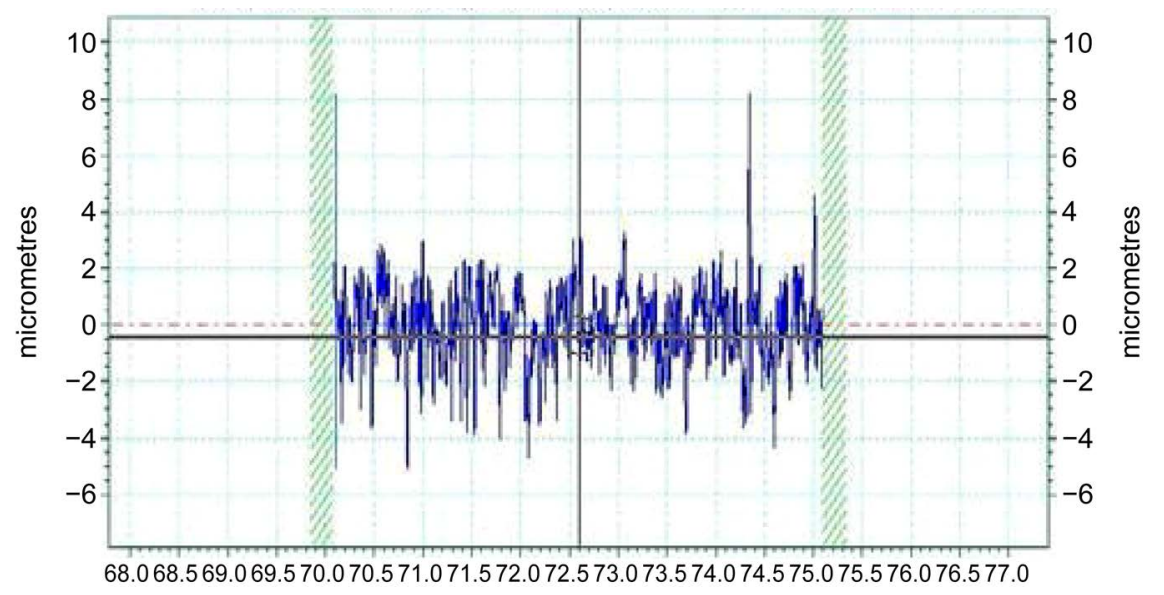

Figure 5. Surface roughness profile of $\mathrm{Cu}$ plate before bonding. 


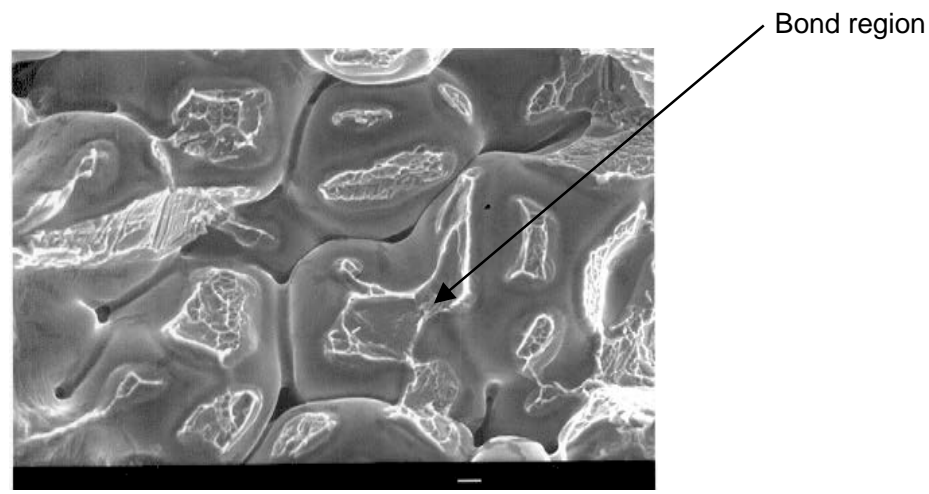

Figure 6. SEM fractograph of surface (failed under tension) of $\mathrm{Ti}-\mathrm{Ti}$ bonded (at $1073 \mathrm{~K}$ for $2 \mathrm{~h}$ ).

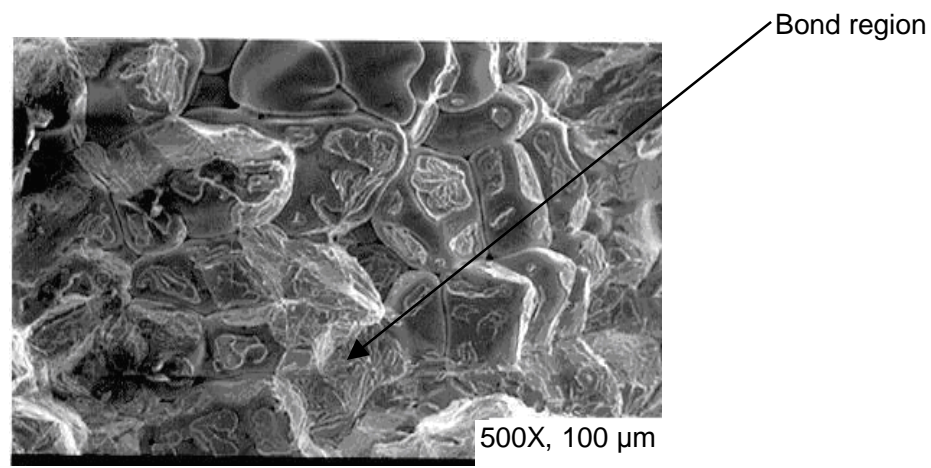

Figure 7. SEM fractograph of surface (failed under tension) of $\mathrm{Ti}-\mathrm{Cu}$ bonded ( at $973 \mathrm{~K}$ for $2 \mathrm{~h}$ ).

$\mathrm{Ti}-\mathrm{Cu}$ bonded at $973 \mathrm{~K}$ for $2 \mathrm{~h}$. It is observed from the fractured surfaces that the mode of fracture of fracture is cleavage having sound metallurgical joint with minimum un-bonded areas.

\subsection{Optical Microstructure of Base Metals, SEM Analysis of Bonded Joints and EDX}

The microstructures of the base material and the interfaces resulting from joining were characterized by optical microscopy $(\mathrm{OM})$ at $100 \mathrm{X}$ magnification as well as using the scanning electron microscopy (SEM). Figure 8 and Figure 9 shows the optical microstructure of commercially pure $\mathrm{Ti}$ and $\mathrm{Cu}$ plates. Figure 10 shows the SEM image of diffusion bonded Ti-Ti plates at $1073 \mathrm{~K}$ for 2 hours under a static force of $250 \mathrm{~N}$ indicating the concentration profile across the interfaces resulting from bonding. In the case of Ti-Ti plates diffused at $1073 \mathrm{~K}$ at 1 hour, the bond centerline consisted of Ti-Ti matrix with small particles of Ti-Ti solid solution just outside the central region. The bond region farthest from the center line consisted of only a solid solution of Ti-Ti. As the bond time is increased to 2 hours at $1073 \mathrm{~K}$, the same microstructure appeared in the bond region but with an increase in the bond width. Note that as the temperature increases the solid solubility also increases. In the case of Ti-Ti diffusion bonding, the formation of intermetallics in the bonding area was totally absent. When Ti 


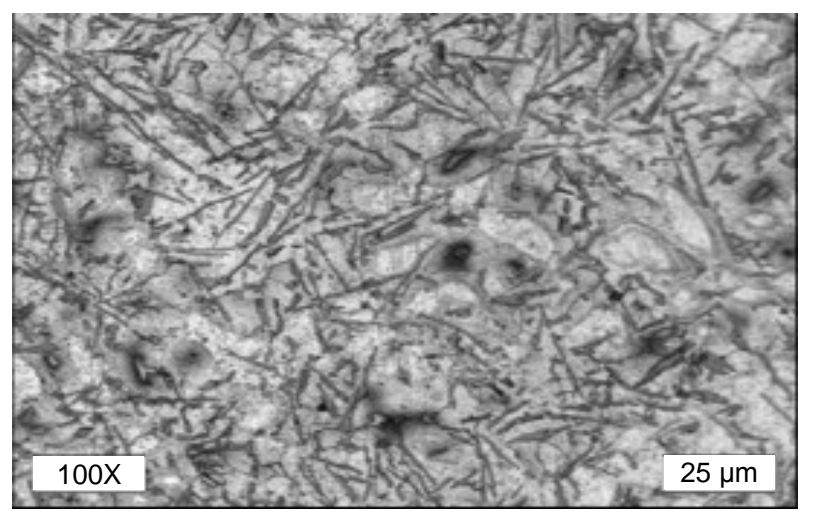

Figure 8. Microstructure of commercially pure Ti plate (grade-2).

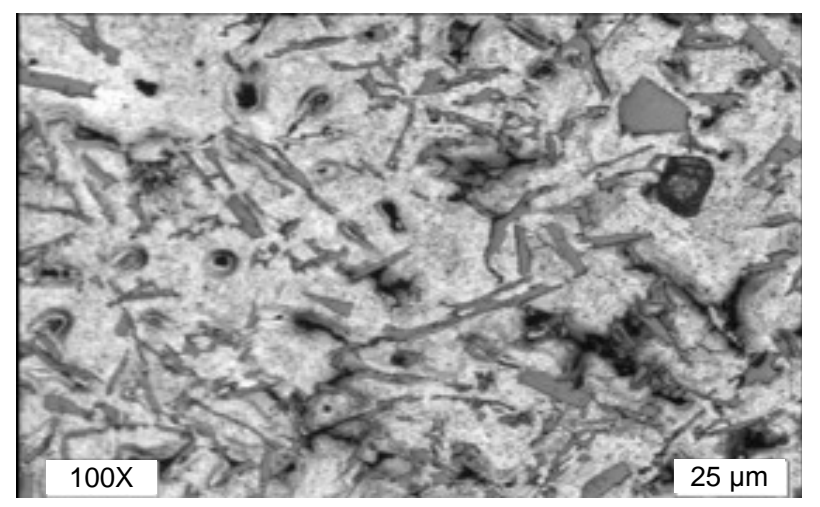

Figure 9. Microstructure of commercially pure $\mathrm{Cu}$ plate.

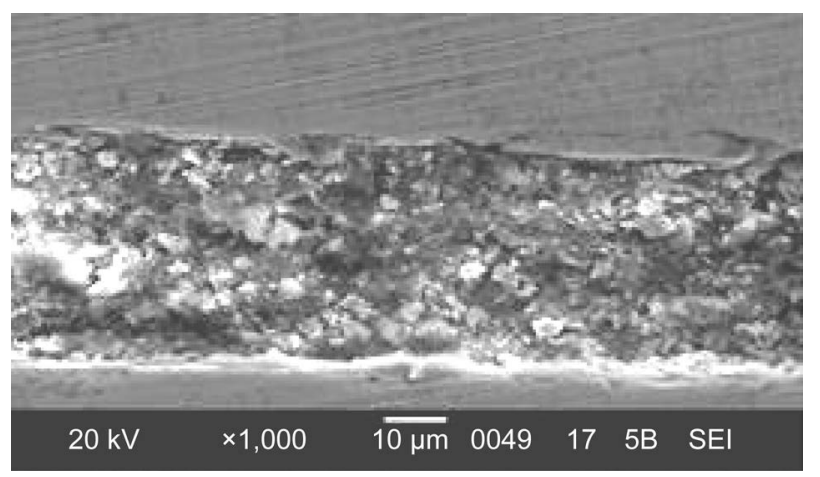

Figure 10. SEM photograph of diffusion bonded Ti-Ti plates (at $1073 \mathrm{~K}, 2$ hours at $250 \mathrm{~N}$ ).

is bonded with $\mathrm{Ti}$, the bond line was not clearly visible until it was etched (8\% $\mathrm{HF}$ and $4 \% \mathrm{HNO}_{3}$ ) and it was not continuous (see Figure 10) having some regions completely bonded while few voids were present elsewhere.

Figure 11 shows the cross section of the diffusion bonded $\mathrm{Ti}-\mathrm{Cu}$ joint at $973^{\circ} \mathrm{C}$ for 2 hours under a static force of $250 \mathrm{~N}$. Although $\mathrm{Cu}$ form intermetallics with $\mathrm{Ti}$, microstructure of the bonded zone was different when $\mathrm{Ti}-\mathrm{Cu}$ was bonded. It is to be remembered here that intermetallics are brittle and they increase hardness by reducing the bond strength a little. At a temperature of $973 \mathrm{~K}$ for 2 hours, the bonding zone consisted of a region of $\mathrm{Ti}-\mathrm{Cu}$ solid solution, a 


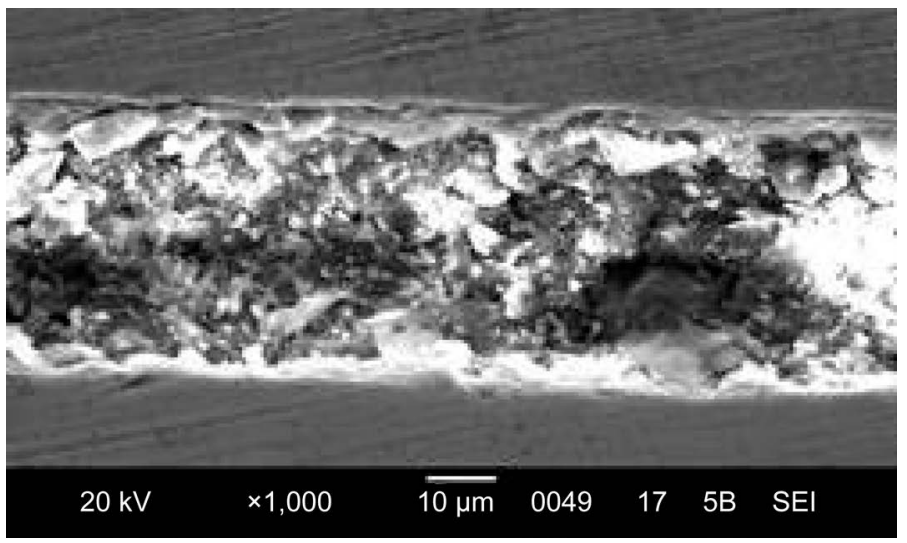

Figure 11. SEM photograph of diffusion bonded Ti-Cu plates (at 973 $\mathrm{K}, 2$ hours at $250 \mathrm{~N})$.

region of different intermetallics and a region of eutectic mixture of Ti (Figure 11). Here the composition of $\mathrm{Cu}$ was discontinuous in the intermetallics region depending on the composition of the intermetallics. When the bonding time is further increased beyond 2 hours (at $973 \mathrm{~K}$ ), the continuous region of different intermetallics disappeared from the bond centerline and the centerline consisted of only the eutectic mixture of $\mathrm{Ti}$ and $\mathrm{Cu}$. Although the melting temperature of $\mathrm{Cu}$ is $680^{\circ} \mathrm{C}$ (or $953 \mathrm{~K}$ ), no evidence was found the existence of residual $\mathrm{Cu}$ in the bond region at $973 \mathrm{~K}$ or little above. Finally, the bond centerline consisted of $\mathrm{Ti}-\mathrm{Cu}$ solid solutions, eutectic mixtures and some small areas of intermetallics, possibly $\mathrm{Ti}_{3} \mathrm{Cu}$. However at $973 \mathrm{~K}$ at 1 hour some pores appeared in the bond region and the pore size decreased a little at higher temperatures.

In both the cases ( $\mathrm{Ti}-\mathrm{Ti}$ and $\mathrm{Ti}-\mathrm{Cu}$ ) the concentration profile indicate that there is a diffusion flux of one atom towards the other in opposite direction and is controlled by grain boundary diffusion. Figure 12 and Figure 13 shows EDX analysis photographs of diffusion bonded $\mathrm{Ti}-\mathrm{Ti}$ and $\mathrm{Ti} \mathrm{Cu}$ at $1073 \mathrm{~K}$ and $973 \mathrm{~K}$ for 2 hours.

\subsection{Hardness of Diffusion Bonded Joints}

To check the mechanical property of the bonded samples, micro hardness tests were performed. Tables 1-4 show the micro hardness of the bonded samples of $\mathrm{Ti}-\mathrm{Ti}$ and $\mathrm{Ti}-\mathrm{Cu}$ bonded plates at different temperatures and time duration. It is observed that the maximum hardness was obtained when $\mathrm{Cu}$ was bonded with $\mathrm{Ti}$ at $973 \mathrm{~K}$ for 2 hours was $367.15 \mathrm{HV}$. This might be due to the presence of intermetallics (not continuous) that are brittle has increased the hardness.

Hardness test results of Ti-Ti plates bonded at 1073 for $1-2$ hours are shown in Table 1 and Table 2. The hardness increased with temperature up to 2 hours of bonding time but decreased when the bonding time was increased beyond 2 hours. The maximum hardness of Ti-Ti achieved was $244.14 \mathrm{HV}$ at $1073 \mathrm{~K}$ for 2 hours. Figure 14 and Figure 15 shows micro hardness test indentation marks for $\mathrm{Ti}-\mathrm{Ti}$ and $\mathrm{Ti}-\mathrm{Cu}$ bonded samples near the bond region at a temperature of $1073 \mathrm{~K}$ and $973 \mathrm{~K}$ for 2 hours respectively. 


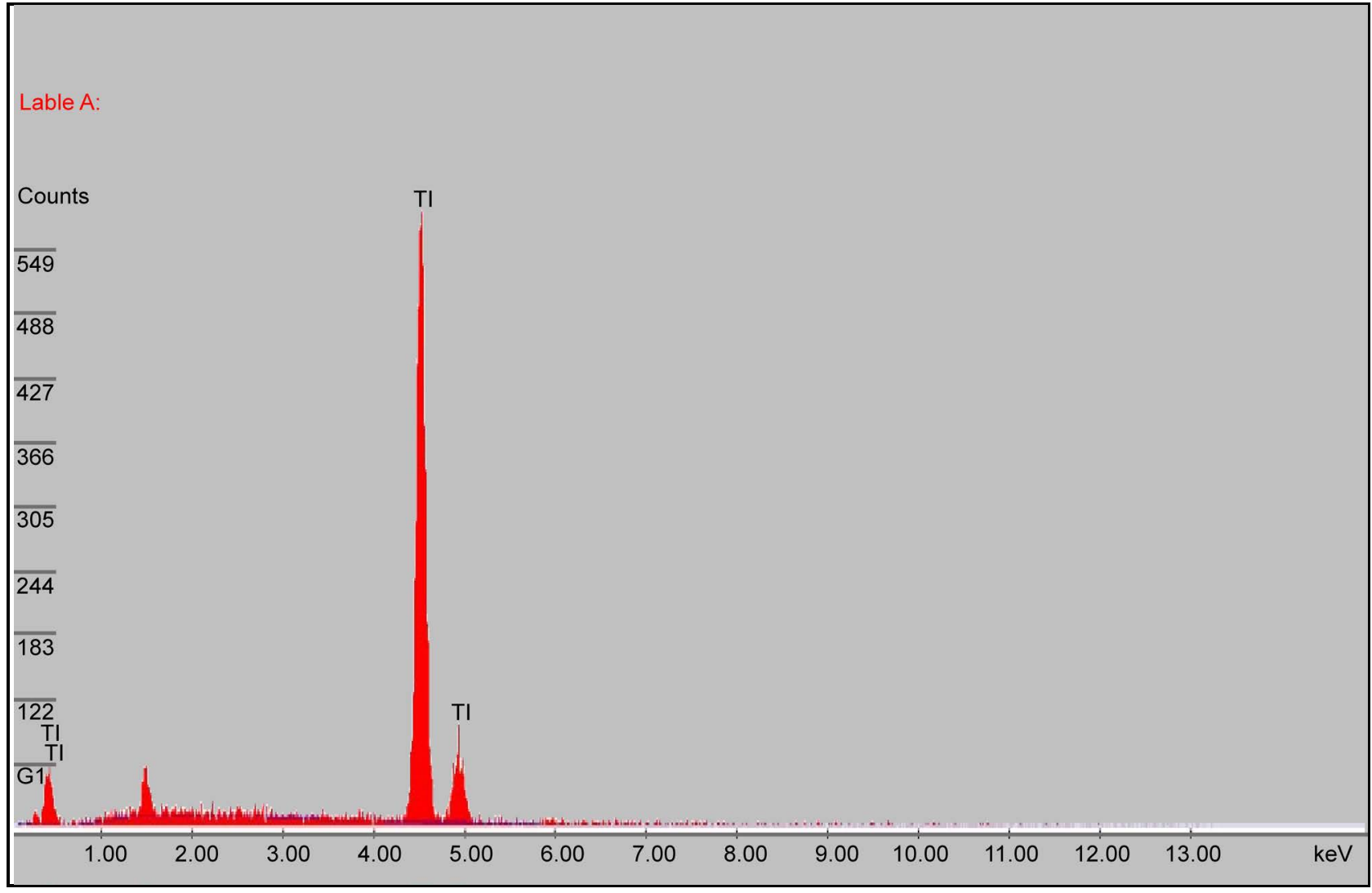

Figure 12. EDS photograph of diffusion bonded Ti-Ti and (at $1073 \mathrm{~K}$ for 2 hours).

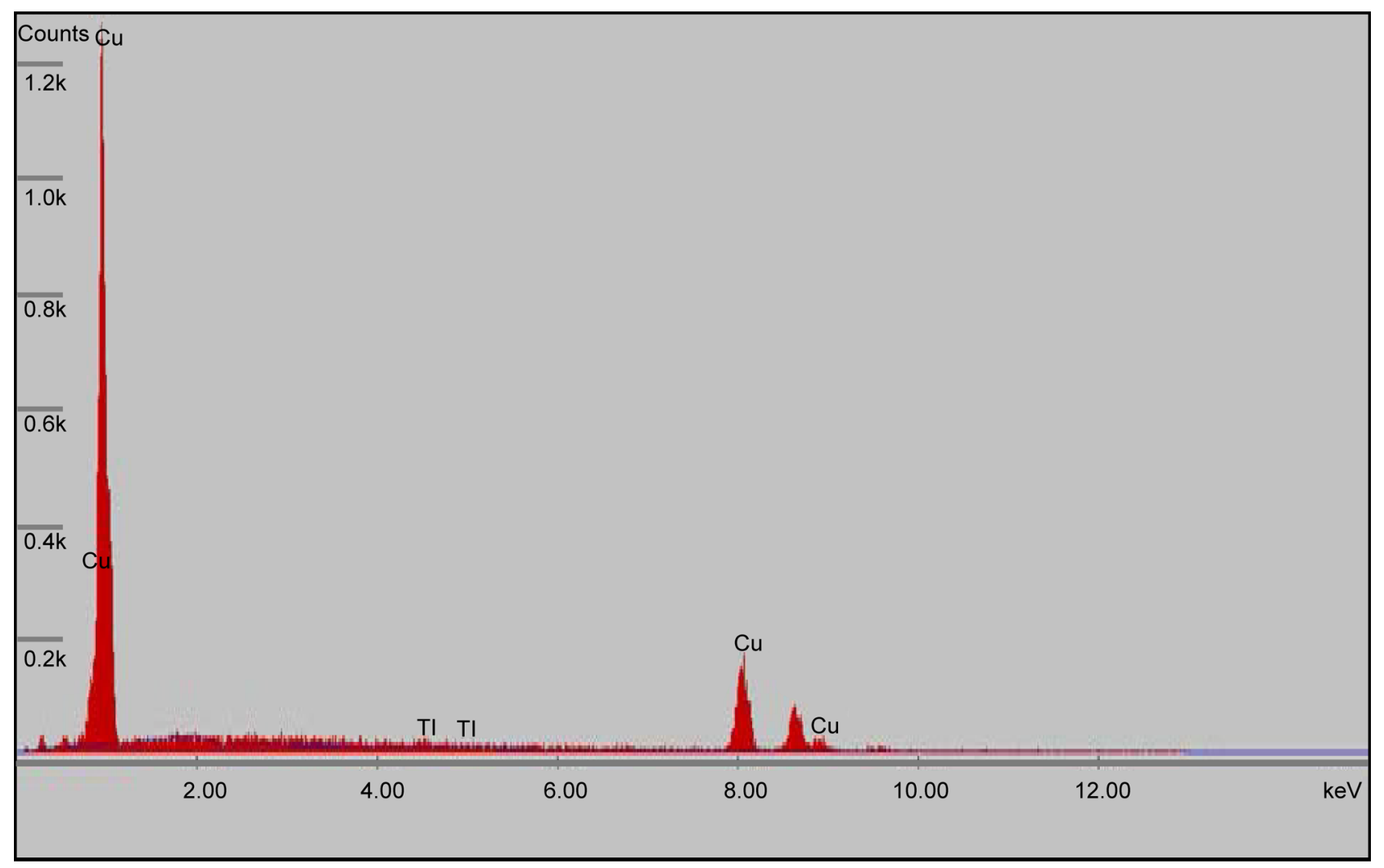

Figure 13. EDS photograph of diffusion bonded Ti-Cu and at ( $973 \mathrm{~K}$ for 2 hours). 
Table 1. Micro hardness test results of Ti-Ti bonded samples (at $973 \mathrm{~K}$ for 1 hour).

\begin{tabular}{ccc}
\hline location & Right side & Left side \\
\hline $50 \mu \mathrm{m}$ & $209.39 \mathrm{HV} 0.3$ & $209.39 \mathrm{HV} 0.3$ \\
$150 \mu \mathrm{m}$ & $197.36 \mathrm{HV} 0.3$ & $201.86 \mathrm{HV} 0.3$ \\
$250 \mu \mathrm{m}$ & $204.64 \mathrm{HV} 0.3$ & $206.52 \mathrm{HV} 0.3$ \\
\hline
\end{tabular}

Table 2. Micro hardness test results of Ti-Ti bonded samples (at $973 \mathrm{~K}$ for 2 hours).

\begin{tabular}{ccc}
\hline location & Right side & Left side \\
\hline At $50 \mu \mathrm{m}$ & $244.14 \mathrm{HV} 0.3$ & $216.33 \mathrm{HV} 0.3$ \\
At $150 \mu \mathrm{m}$ & $198.25 \mathrm{HV} 0.3$ & $207.47 \mathrm{HV} 0.3$ \\
At $250 \mu \mathrm{m}$ & $218.37 \mathrm{HV} 0.3$ & $209.39 \mathrm{HV} 0.3$ \\
\hline
\end{tabular}

Table 3. Micro hardness test results of Ti-Cu bonded samples (at $1073 \mathrm{~K}$ for 1 hour).

\begin{tabular}{ccc}
\hline location & Right side & Left side \\
\hline $50 \mu \mathrm{m}$ & $273.31 \mathrm{HV} 0.3$ & $297.93 \mathrm{HV} 0.3$ \\
$150 \mu \mathrm{m}$ & $231.28 \mathrm{HV} 0.3$ & $309.77 \mathrm{HV} 0.3$ \\
$250 \mu \mathrm{m}$ & $222.55 \mathrm{HV} 0.3$ & $229.05 \mathrm{HV} 0.3$ \\
\hline
\end{tabular}

Table 4. Micro hardness test results of Ti-Cu bonded samples (at $1073 \mathrm{~K}$ for 2 hours).

\begin{tabular}{ccc}
\hline location & Right side & Left side \\
\hline $50 \mu \mathrm{m}$ & $331.75 \mathrm{HV} 0.3$ & $367.15 \mathrm{HV} 0.3$ \\
$150 \mu \mathrm{m}$ & $339.61 \mathrm{HV} 0.3$ & $367.15 \mathrm{HV} 0.3$ \\
$250 \mu \mathrm{m}$ & $315.05 \mathrm{HV} 0.3$ & $364.91 \mathrm{HV} 0.3$ \\
\hline
\end{tabular}

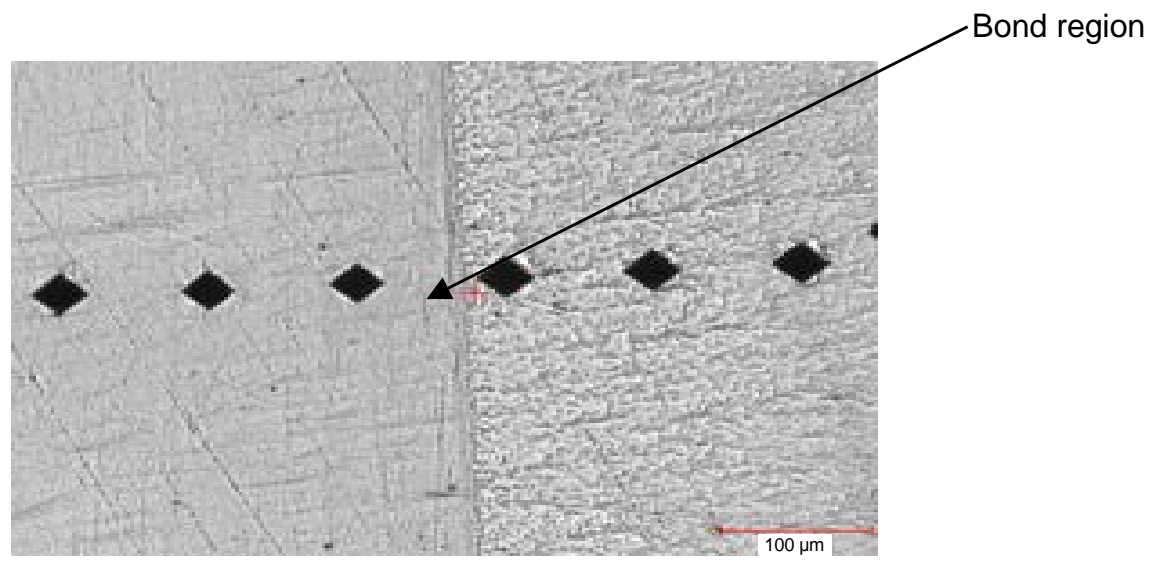

Figure 14. Micro hardness test indentation marks for Ti-Ti bonded sample (at $1073 \mathrm{~K}$ for 2 hours). 


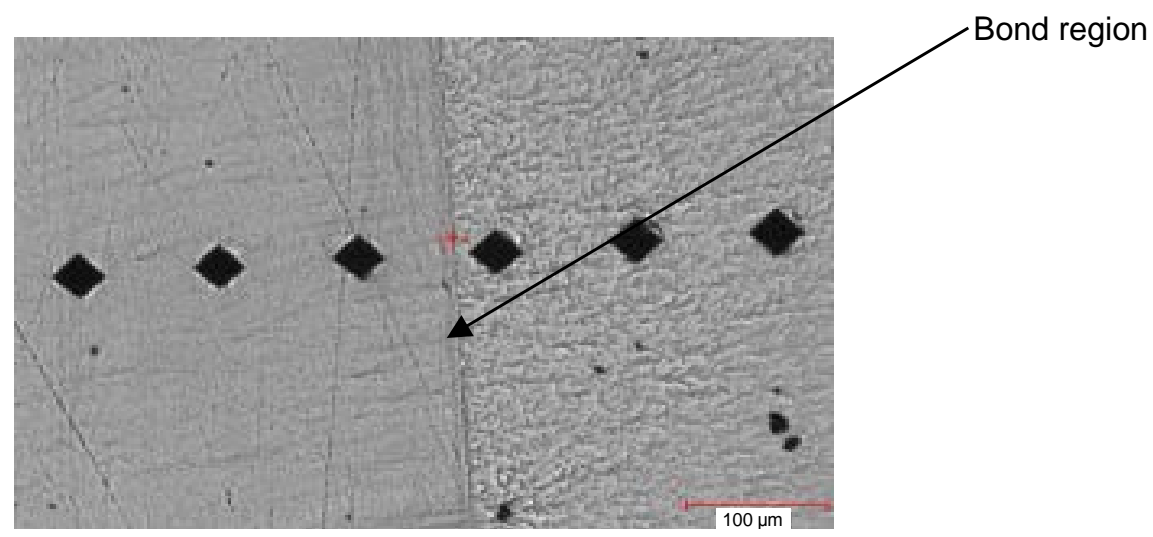

Figure 15. Micro hardness test indentation marks for Ti-Cu bonded sample (at $973 \mathrm{~K}$ for 2 hours).

\section{Conclusion}

The present research indicated the diffusion bonding of commercially pure $\mathrm{Ti}$ and $\mathrm{Cu}$ plates under a static force without any interlayers. Bond hardness with minimum pores mainly depends on the bond temperature (1073 - $973 \mathrm{~K}$ ), the bond time $(1-2 \mathrm{~h})$ and static force applied $(250 \mathrm{~N})$ applied during bonding. Use of vacuum and diffusion pump avoids reaction due to oxidation during bonding. The maximum hardness ( $367.15 \mathrm{HV}$ ) was obtained in the case of Ti-Cu bonded plates and the joint reached $53 \%$ of the hardness of the base metal. This is mainly because of formation of continuous band of hard intermetallics. Hardness was low in the case of Ti-Ti bonded plates only solid solution of Ti-Ti was appeared but no intermetallics was found in the bonded region. In addition to bonding temperature, bonding time, static force, surface preparation was found to be very important for atomic diffusion and hence the bond hardness.

\section{References}

[1] He, B.H., Huang, B.Y., Zhou, K.C., Ou, W.P. and Cheng, X.Q. (1997) Influence of Microstructure of Ti-Al Based Alloy on the Mechanical Properties at Elevated Temperature. The Chinese Journal of Non-Ferrous Metals, 7, 75-79. (In Chinese)

[2] Lin, J.G., Zhang, Y.G. and Chen, C.Q. Effects of Lamellar Boundaries on Creep Behavior of Pst Crystals of TiAl Alloys. Transactions of Nonferrous Metals Society of China, 8, 562-566.

[3] Equations from "An Investigation of the Fracture Behavior of Diffusion-Bonded Ti6Al4V/TiC/10p” from 2-8.

[4] Lin, J.G, Yu, G.S. and Huang, Z. (2001) A Novel Approach to the Solid Bonding of a TiAl Alloy. Journal of Materials Science Letters, 20, 1671-1673. https://doi.org/10.1023/A:1012417201722

[5] da Silva, A.A.M., dos Santos, J.F. and Strohaecker, T.R. (2006) An Investigation of the Fracture Behaviour of Diffusion-Bonded Ti6Al4V/TiC/10p. Composites Science and Technology, 66, 2063-2068. https://doi.org/10.1016/j.compscitech.2005.12.018

[6] Shermon, P.G. (1994) Introduction to Solid State Chemistry. 3rd Edition, Buttersworth Publication, UK.

[7] Kocak, M. (1989) Diffusion Bonding of Investment Castings. Journal of Materials 
Science, 41, 1-5.

[8] Kim, Y.W. (1989) Intermetallic Alloys Based on Gamma Titanium Aluminide. Journal of Metals, 41, 24-30.

[9] Kim, Y.W. and Dimlduk, D.M. (1991) Progress in the Understanding of Gamma Titanium Aluminides. Materials Science and Engg-B, 43, 40-47.

[10] Rathod, P. and Sinha, A. (2009) Mechanical Properties of Diffusion Bonded Ti Alloys in Liquid State. International Journal of Applied Sciences, 12, 56-63.

[11] Almonds, P. (2014) Diffusion Bonding of Ti Alloy with Ag-Cu-Zn Interlayers. Journal of Advanced Materials Research, 23, 89-97.

[12] Kundu, S., Jayaram, S. and Santhosh, M. (2015) Characterization of Ti Alloy Diffusion Bonds with $\mathrm{Cu}$ Interlayer. Materials and Design, 67, 123-131.

[13] Dezellus, N., Ranolda, K. and Kishore, Y. (2015) Fracture Behavior of Ti Diffusion Bonded with $\mathrm{Cu}-\mathrm{Ag}$ Interlayers. Journal of Fracture Mechanics, 34, 77-85.

Submit or recommend next manuscript to SCIRP and we will provide best service for you:

Accepting pre-submission inquiries through Email, Facebook, LinkedIn, Twitter, etc. A wide selection of journals (inclusive of 9 subjects, more than 200 journals)

Providing 24-hour high-quality service

User-friendly online submission system

Fair and swift peer-review system

Efficient typesetting and proofreading procedure

Display of the result of downloads and visits, as well as the number of cited articles Maximum dissemination of your research work

Submit your manuscript at: http://papersubmission.scirp.org/

Or contact ojcm@scirp.org 